\title{
Shikonin promotes adriamycin-induced apoptosis by upregulating caspase- 3 and caspase-8 in osteosarcoma
}

\author{
QING YANG ${ }^{1,2^{*}}$, SUOYUAN LI ${ }^{3 *}$, ZEZE FU $^{4 *}$, BINHUI LIN $^{3}$, ZIFEI ZHOU ${ }^{4}$, \\ ZHUOYING WANG ${ }^{4}$, YINGQI HUA ${ }^{4}$ and ZHENGDONG CAI ${ }^{1}$ \\ ${ }^{1}$ Department of Orthopedics, Nanjing Medical University Shanghai Tenth People's Hospital, Nanjing, Jiangsu 210029; \\ ${ }^{2}$ Department of Orthopedics, Zhongshan Hospital, Qingpu Branch, Fudan University, \\ Shanghai 201700; ${ }^{3}$ Department of Orthopedics, Shanghai General Hospital, Nanjing Medical University; \\ ${ }^{4}$ Department of Orthopedics, Shanghai General Hospital, Shanghai Jiao Tong University, Shanghai 201600, P.R. China
}

Received February 19, 2016; Accepted February 9, 2017

DOI: $10.3892 / \mathrm{mmr} .2017 .6729$

\begin{abstract}
Osteosarcoma is the most common primary malignant bone tumor. Cancer cells employ a host of mechanisms to develop resistance to adriamycin (ADM) or other chemotherapeutic drugs. Shikonin (SK), an active constituent extracted from a Chinese medicinal herb, has been shown to cooperate with ADM in the treatment of osteosarcoma and certain other types of cancer by contributing to the response rate of chemotherapy and the side effects. The aim of the present study was to investigate the role and underlying mechanism of SK in chemotherapy for osteosarcoma. In the present study, a CCK-8 assay was performed to assess cell survival rate in vitro. Western blot analysis was performed to determine the expression levels of B-cell lymphoma 2-associated X protein (Bax), caspase-3, caspase-8, and poly (ADP-ribose) polymerase (PARP). Flow cytometry was used to analyze cell cycle and cell death. The survival rate of cells decreased significantly in a dose- and time-dependent manner when treated with a combination of SK and ADM. Western blot analysis revealed increased expression levels of Bax, caspase-3, caspase- 8 and PARP in U2OS and MG63 cells $48 \mathrm{~h}$ following treatment with SK and ADM. Flow cytometric analysis showed that the combined treatment of SK and ADM significantly induced apoptosis in the osteosarcoma cells. Taken together SK cooperated with ADM
\end{abstract}

Correspondence to: Dr Zhengdong Cai, Department of Orthopedics, Nanjing Medical University Shanghai Tenth People's Hospital, 101 Longmian Street, Nanjing, Jiangsu 210029, P.R. China E-mail: zhdcai@gmail.com

Dr Yingqi Hua, Department of Orthopedics, Shanghai General Hospital, Shanghai Jiao Tong University, 650 Xinsongjiang Road, Shanghai 201600, P.R. China

E-mail: hua_yingqi@163.com

*Contributed equally

Key words: osteosarcoma, apoptosis, shikonin, adriamycin, caspase-3, caspase-8 to promote apoptosis, possibly by inducing caspase-3- and caspase-8-dependent apoptosis. SK may be a potential enhancer in the treatment of drug-resistant primary osteosarcoma.

\section{Introduction}

Osteosarcoma is the most common primary malignant bone tumor, which accounts for $\sim 60 \%$ of all bone sarcomas $(1,2)$. The introduction of chemotherapy has led to a marked improvement in the prognosis of patients with localized osteosarcoma. Long-term survival rates, previously $<20 \%$, have improved to $65-70 \%$ following the advent of multiagent chemotherapy regimens (3). However, the survival rate for patients with osteosarcoma remains low. A significant proportion of osteosarcomas cases are not sensitive to conventional chemotherapy, with long-term survival rates of $\sim 20 \%$ (4).

Adriamycin (ADM) is one of the most widely used chemotherapeutic drugs for the treatment of human osteosarcoma. However, the acquisition of ADM resistance is common in patients with osteosarcoma, leading to local and distant failure. In addition, high doses of ADM lead to toxic side effects in patients with osteosarcoma $(5,6)$. Therefore, an alternative strategy is required, which enables a decrease in the dose of chemotherapeutics required, but enhances the sensitivity of cancer cells to chemotherapeutics.

Natural products are important in cancer chemotherapy due to their beneficial pharmacological activities and low toxicity. Tumor therapy with traditional Chinese herbs, including curcumin (7-9), triptolide (10) and Danshen (11) is becoming increasingly attractive (12). Shikonin (SK), an effective constituent purified from the Chinese medicinal herb, Lithospermum erythrorhixon, has been shown to exert antitumor effects by inhibiting pyruvate kinase-M2 (PKM2). PKM2, which catalyzes the final rate-limiting step in glycolysis, is vital for cancer cell proliferation and is universally overexpressed in cancer cells (13). SK was previously shown to be a cytotoxic DNA-binding agent (14). Furthermore, SK and its analogs have been shown to induce minimal cancer drug resistance (15).

To decrease the side effects and enhance the efficacy of traditional Chinese medicines, different combinations of medicinal herbs have been used as an alternative strategy 
for cancer therapy. The present study aimed to analyze the in vitro effects of the combination treatment of SK and ADM on human osteosarcoma cell lines.

\section{Materials and methods}

Cell lines and cell culture. The U2OS and MG63 human osteosarcoma cell lines were obtained from American Type Culture Collection (Manassas, VA, USA). All cells were cultured in high glucose Dulbecco's modified Eagle's medium (DMEM-h) supplemented with $10 \%$ fetal bovine serum (FBS), $100 \mathrm{U} / \mathrm{ml}$ penicillin and $100 \mu \mathrm{g} / \mathrm{ml}$ streptomycin (all from Thermo Fisher Scientific, Inc., Waltham, MA, USA) in a humidified incubator at $37^{\circ} \mathrm{C}$ in $5 \% \mathrm{CO}_{2}$.

Drugs and antibodies. Purified SK (>98\%) was purchased from Shanghai Tauto Biotech Co., Ltd. (Shanghai, China). ADM ( $5 \mathrm{mmol} / \mathrm{l}$ ) was purchased from Selleck Chemicals (Houston, TX, USA). Stock solutions were produced in dimethyl sulfoxide (Sigma-Aldrich; Merck Millipore, Darmstadt, Germany) at a concentration of $50 \mathrm{mM}$ and stored in the dark at $-20^{\circ} \mathrm{C}$. SK and ADM were used at final concentrations of 0.01 and $0.1 \mu \mathrm{M}$, respectively, by diluting the stock solution in DMEM-h. The antibodies used for western blot analysis were as follows: Rabbit anti-actin (Santa Cruz Biotechnology, Inc., Dallas, TX, USA; cat no. sc130657), anti-B-cell lymphoma 2-associated X protein (Bax; cat no. ab7977), anti-caspase-3 (cat no. 9664), anti-caspase-8 (cat no. ca0689), and anti-poly (ADP-ribose) polymerase (PARP; cat no. 9542) (all from Cell Signaling Technology, Inc., Danvers, MA, USA).

CCK- 8 assay. The U2OS and MG63 osteosarcoma cells $\left(0.5 \times 10^{4} /\right.$ well $)$ were seeded into 96 -well plates and cultured overnight for adherence of cells. The cells were then treated with SK $(0.01 \mu \mathrm{M}), \operatorname{ADM}(0.1 \mu \mathrm{M})$ or a combination of SK $(0.01 \mu \mathrm{M})$ and $\operatorname{ADM}(0.1 \mu \mathrm{M})$ for $48 \mathrm{~h}$ at $37^{\circ} \mathrm{C}$. Cells incubated with DMEM-h were used as a control group. Following incubation for $48 \mathrm{~h}$, the supernatant was removed and $2 \mathrm{ml}$ CCK-8 (Beyotime Institute of Biotechnology, Shanghai, China) was added into each well and incubated for $1 \mathrm{~h}$ to solubilize the blue-purple crystals of formazan. The absorbance was then measured at $490 \mathrm{~nm}$ using an ELX800 microplate reader (BioTek Instruments, Inc., Winooski, VT, USA). The survival rate was calculated according to the following formula: Survival rate $=$ absorbance of treatment/absorbance of control x $100 \%$.

Flow cytometric analysis. The U2OS and MG63 osteosarcoma cells $\left(2 \times 10^{5} /\right.$ well) were plated in 6 -well plates and synchronized with DMEM-h containing 10\% FBS. Following incubation for $8 \mathrm{~h}$, the SK-treated cells $(0.01 \mu \mathrm{M})$, ADM-treated cells $(0.1 \mu \mathrm{M})$ and combination treated-cells were treated with $0.01 \mu \mathrm{M}$ SK and $0.1 \mu \mathrm{M}$ ADM for $48 \mathrm{~h}$ at $37^{\circ} \mathrm{C}$. The cells were then collected and washed twice in cold PBS. The cells were mixed in $100 \mu \mathrm{l}$ of $1 \mathrm{X}$ binding buffer and incubated at room temperature for $15 \mathrm{~min}$ with Annexin-V/7AAD (eBioscience, Inc., San Diego, CA, USA) double staining solution. The stained cells were analyzed using flow cytometry. The percentages of necrotic cells and the proportions of cells in different cell cycle stages were calculated using BD Accuri C6 software (C Flow Sampler Analysis version 1.0.208.2 Installer; BD Biosciences, San Jose, CA, USA).

Western blot analysis. The U2OS and MG63 cells were treated with the different solutions (DMEM-h, SK, ADM, or a combination of SK and ADM) for $48 \mathrm{~h}$. The cells were then washed twice with PBS solution and lysed in RIPA lysis buffer (Beyotime Institute of Biotechnology) containing protease inhibitors (Thermo Fisher Scientific, Inc.). The tumor cells were retrieved from $-80^{\circ} \mathrm{C}$ storage and immersed rapidly in liquid nitrogen. The resulting powder was lysed in RIPA lysis buffer containing protease inhibitors. Protein concentrations were determined using a Pierce BCA protein assay kit (Thermo Fisher Scientific, Inc.). Equivalent quantities of total protein $(50 \mu \mathrm{g})$ were boiled and electrophoretically separated on a $10 \%$ polyacrylamide gel at 80 volts. The proteins were then transferred onto a nitrocellulose filter membrane. The membranes were blocked for 60 min with a $5 \%$ milk solution prepared in PBS, and then incubated overnight at $4^{\circ} \mathrm{C}$ with a 1:1,000 dilution of the primary antibodies (Bax, PARP, caspase-3, caspase- 8 and actin). The membranes were then washed three times (10 min each) with Tween 20 (1:1,000 dilution)-PBS and incubated for $1 \mathrm{~h}$ with the appropriate peroxidase-conjugated secondary antibody (1:1,000 dilution; Odyssey Mouse IgG F(c) Antibody IRDye ${ }^{\circledR} 800 \mathrm{CW}$ Conjugated; LI-COR Biotechnology, Lincoln, NE, USA; cat no. $610-131-003)$ at $37^{\circ} \mathrm{C}$. The membranes were washed three times with Tween 20-PBS (10 min each) and developed using the Odyssey two-color infrared laser imaging system (LI-COR Biosciences, Lincoln, NE, USA). The signal generated by actin was used as an internal control.

Statistical analysis. Statistical analysis was performed using GraphPad Prism 5 (GraphPad Software, Inc., La Jolla, CA, USA). Data are expressed as the mean \pm standard deviation and comparisons between two groups were performed using Student's t test. $\mathrm{P}<0.05$ was considered to indicate a statistically significant difference.

\section{Results}

Treatment with SK and with ADM decreases cell survival of osteosarcoma cells. The U2OS osteosarcoma cells were treated with different concentrations of ADM, or with $0.1 \mu \mathrm{M}$ ADM for different durations. The U2OS cells were also treated with different concentrations of SK for $48 \mathrm{~h}$, or with $0.01 \mu \mathrm{M}$ SK for different durations. The results showed that ADM (Fig. 1A and B) and SK (Fig. 1C and D) increased apoptosis of the osteosarcoma cells in a dose- and time-dependent manner.

SK and ADM act synergistically to decrease osteosarcoma cell survival. A CCK-8 assay was used to measure the cell survival rates of the U2OS and MG63 osteosarcoma cells, which were treated with DMEM-h, SK $(0.01 \mu \mathrm{M}), \mathrm{ADM}(0.1 \mu \mathrm{M})$, or SK $(0.01 \mu \mathrm{M})$ and $\operatorname{ADM}(0.1 \mu \mathrm{M})$ for $48 \mathrm{~h}$ (Fig. 2). The results revealed that SK and ADM acted synergistically to decrease the survival rates of the osteosarcoma cells.

SK enhances the apoptotic effect of ADM in osteosarcoma. The present study further examined differences in cell 

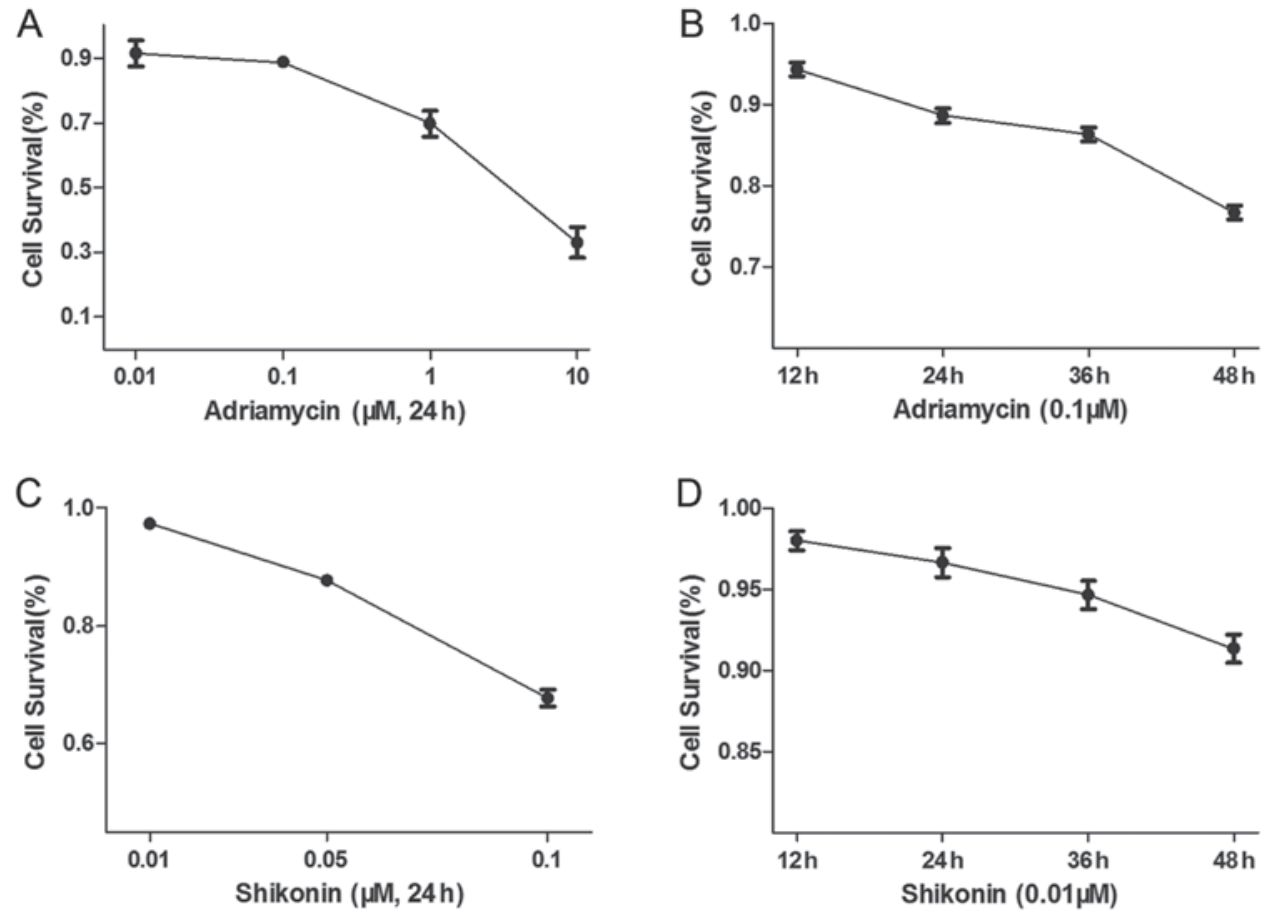

Figure 1. ADM and SK cause increases in apoptosis of osteosarcoma cells. ADM caused a reduction in cell survival of the U2OS cells in a (A) dose-dependent and (B) time-dependent manner. SK caused a reduction in cell survival in a (C) dose-dependent and (D) time-dependent manner. SK, shikonin; aDM, Adriamycin.
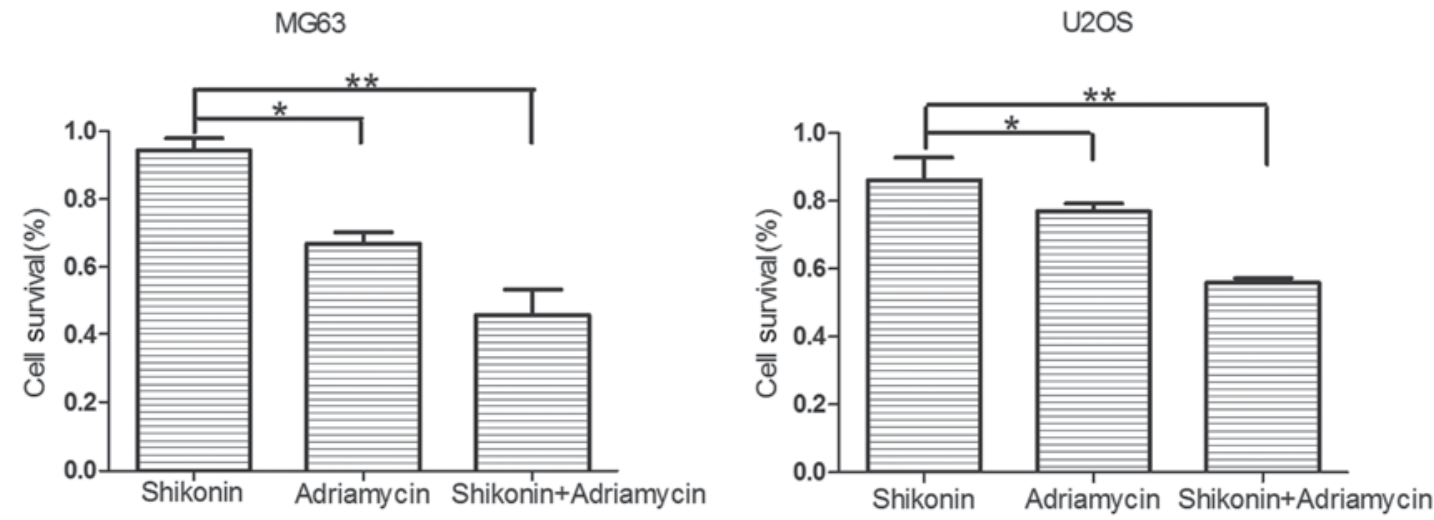

Figure 2. Shikonin and adriamycin act synergistically to increase apoptosis in osteosarcoma cells. ${ }^{*} \mathrm{P}<0.05 ;{ }^{* *} \mathrm{P}<0.01$.

apoptosis following treatment of osteosarcoma cells (U2OS and MG63) with SK and/or ADM. The results of the flow cytometric analysis revealed significant increases in cell apoptosis following treatment with SK and ADM for $48 \mathrm{~h}$ (Fig. 3). These data suggested that SK induced the apoptotic effects of ADM on the osteosarcoma cells.

SK and ADM promote expression levels of caspase -3 and -8 in osteosarcoma. Caspase- 3 and caspase- 8 are considered crucial modulators of apoptosis. As shown in Fig. 4, the protein levels of caspase- 3 and caspase- 8 increased significantly in the U2OS and MG63 cells following treatment with SK and ADM for $48 \mathrm{~h}$ at the lowest drug concentrations $(\mathrm{P}<0.05)$. The data indicated that SK promoted ADM-induced cell death of the osteosarcoma cells by activating caspase-3-and caspase-8-dependent apoptosis.

\section{Discussion}

Osteosarcoma is the most common type of primary malignant tumor of bone and is treated predominantly by surgical resection. However, chemotherapy is important in preoperative and postoperative treatment. Clinical studies have shown that the most commonly used osteosarcoma chemotherapeutic drug, ADM, exhibits an effective rate of only $\sim 40 \%$ when used as a single agent (16). The limited efficacy of cytotoxic chemotherapy remains a key obstacle in the treatment of advanced osteosarcoma.

The combined effect of two or more drugs can be superior to that of a single drug in chemotherapy. Combination therapy can increase the rate of tumor cell death and decrease the growth of tumor cells during treatment. As a result, toxic side effects of chemotherapeutic drugs are commonly found in 


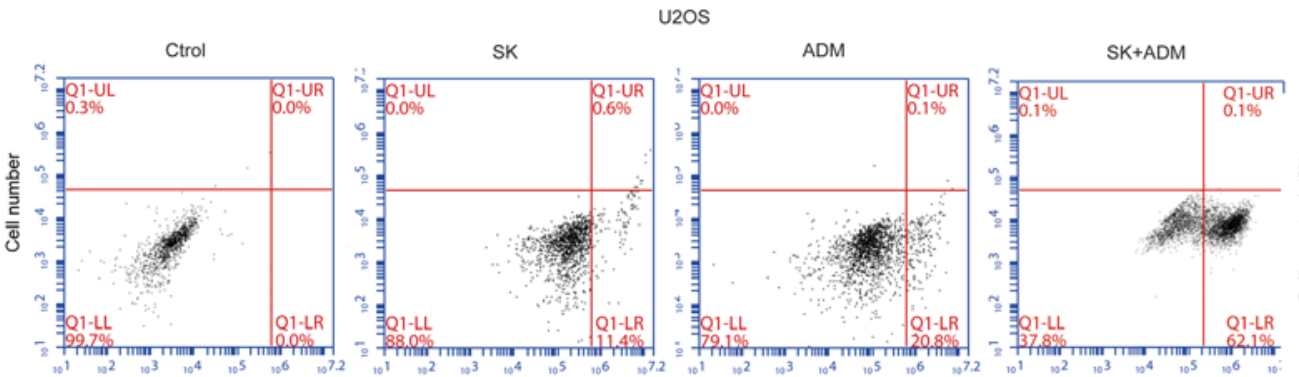

Relative fluorescence intensity (arbitrary unit, A.U.)

MG63
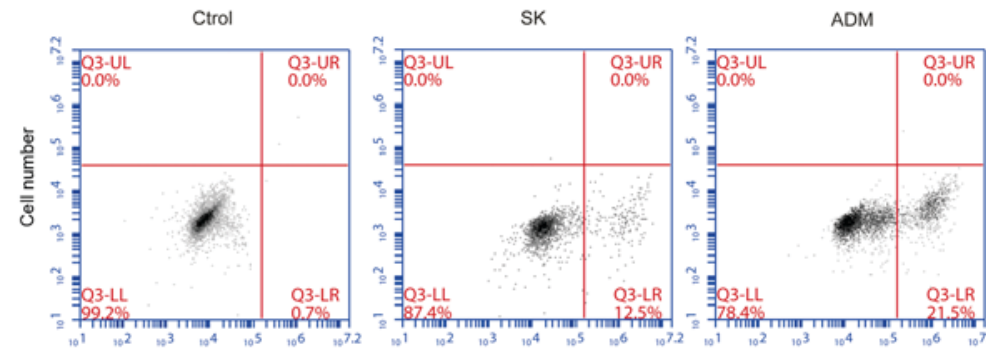

Relative fluorescence intensity (arbitrary unit, A.U.)

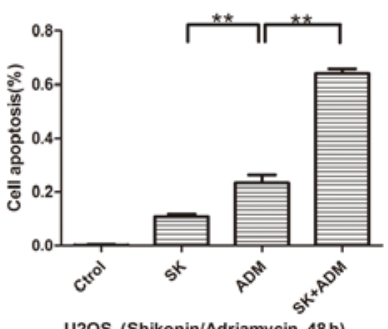

U2OS (Shikonin/Adriamycin, 48 h)

Figure 3. Treatment with SK combined with ADM for $48 \mathrm{~h}$ increases osteosarcoma apoptosis. In the U2OS and MG63 cells, apoptosis was significantly higher in the ADM group, compared with the SK group. Apoptosis in the SK+ADM group was higher, compared with that in the SK group. ${ }^{* *} \mathrm{P}<0.01$. SK, shikonin; ADM, Adriamycin; Ctrol, control.
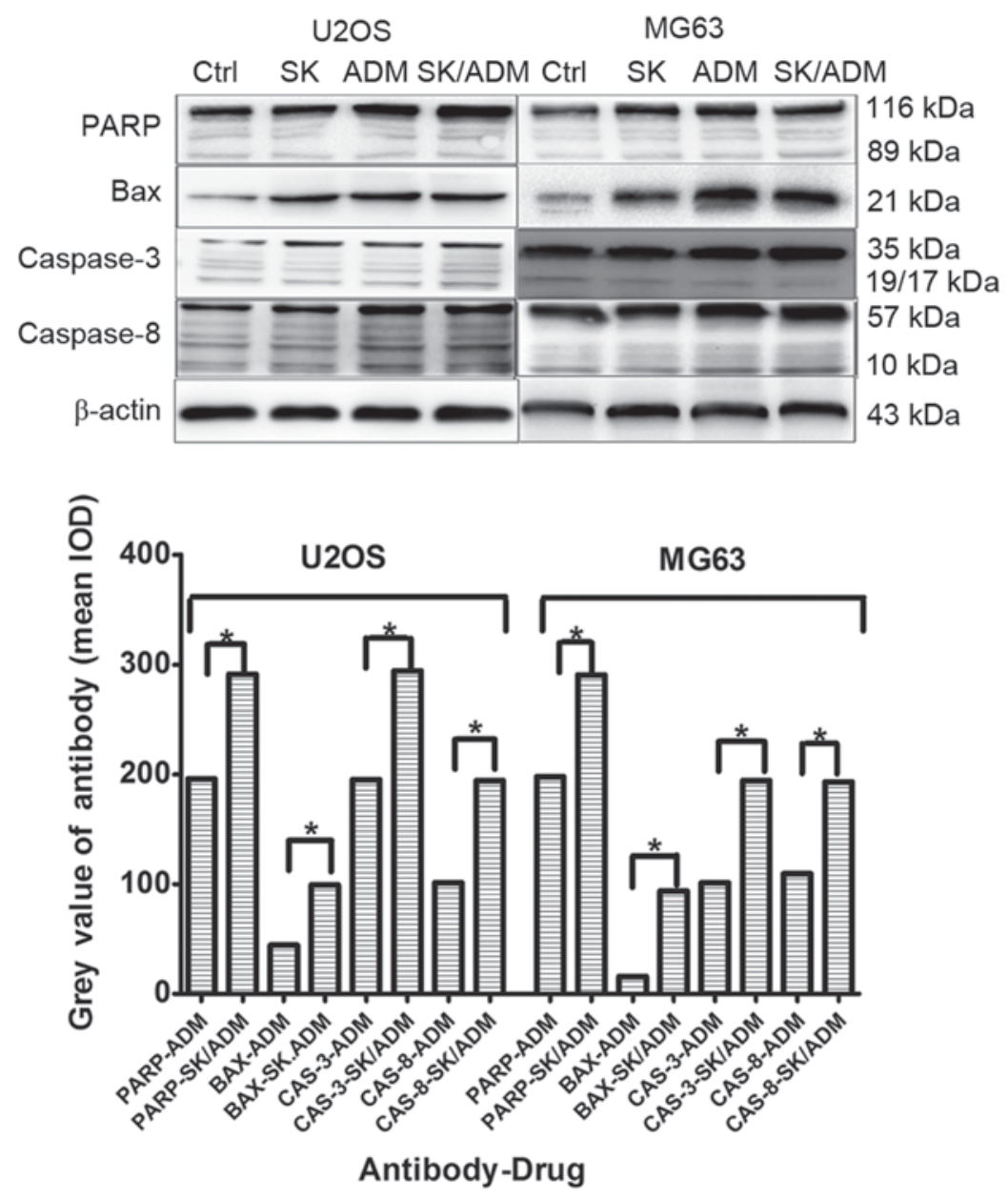

Figure 4. Protein levels of caspase-3 and caspase- 8 increase in osteosarcoma cells treated with SK and ADM. Following treatment of the U2OS and MG63 cells with SK and ADM for $48 \mathrm{~h}$, protein levels of caspase-3 and caspase- 8 were higher, compared with those in the groups treated with SK or ADM alone. "P<0.05. Ctrl, control; SK, shikonin; ADM, adriamycin; PARP, poly (ADP-ribose) polymerase; BAX, B-cell lymphoma 2-associated X protein. 
patients with osteosarcoma. In addition, long-term exposure of the tumor to certain drugs can lead to drug resistance. However, the addition of a second drug markedly reduces the incidence of drug resistance, particularly when the mechanism of drug-induced cell death varies significantly between the two drugs. Drug resistance in cancer is tightly associated with the apoptotic pathway, including the overexpression of anti-apoptotic proteins, mutations in pro-apoptotic proteins and reduction of caspases (17-19). For these reasons, $40 \%$ patients with osteosarcoma do not respond to commonly used anticancer drugs.

ADM is the most commonly used chemotherapeutic drug for the clinical treatment of bone tumors. It exerts antitumor effects by targeting the activity of topoisomerase II $(20,21)$. In addition, ADM is a not a cell cycle-specific drug, being involved in various stages of the cell cycle and inducing cellular apoptosis $(22,23)$. The use of PEGylated liposomal doxorubicin has become a novel treatment strategy for patients with cancer (24). As a traditional chemotherapeutic drug, ADM has inevitable side effects and drug resistance. The treatment of cancer patients with PEGylated liposomal ADM (24) increases drug sensitivity to a certain extent and improves side effects. However, the potential limitations, including the complicated formulation process, potential toxic effects to humans and high medical costs of ADM, have limited the use of liposomal ADM.

As a natural product, SK is important in cancer chemotherapy owing to its beneficial pharmacological activities and low toxicity. SK has also been identified as a cytotoxic DNA-binding agent (14). Furthermore, SK and its analogs have been shown to induce minimal cancer drug resistance (15).

Compared with ADM and its different forms (24), SK has inherent advantages, including being a pure and natural product, showing low toxicity, causing few side effects, exhibiting low drug resistance, being low cost. It also shows high cooperative activity with other anticancer drugs $(14,15)$.

ADM, a classic bone tumor chemotherapeutic drug, and SK, a novel Chinese herb, cooperate in human tumor cell lines and interact to produce apoptotic effects.

In the present study, U2OS and MG63 human tumor cell lines were examined to examine the efficacy of SK in combination with ADM on osteosarcoma. It was found that SK promoted ADM-induced apoptosis at the lowest drug concentrations in osteosarcoma. In addition, SK enhanced the sensitivity of ADM at a low toxicity. Decreases in the required dosage of ADM and expected clinical side effects were observed.

Previous studies $(14,15)$ have shown that SK induces antitumor effects via two major mechanisms: Inducing osteosarcoma necrosis and promoting apoptosis of osteosarcoma cells. Few studies have reported on the use of this drug as a synergistic antitumor agent. Thus, investigating the antitumor mechanism of SK is of important clinical significance.

Caspase- 3 and caspase- 8 are considered to be crucial modulators of apoptosis (25). In the present study, it was found that the protein levels of caspase- 3 and caspase- 8 were significantly increased following treatment with SK and ADM at low concentrations in the U2OS and MG63 osteosarcoma cell lines. The levels of Bax and PARP were also significantly increased (26), further validating the apoptotic pathway.
These results indicated that SK induced cell death in U2OS and MG63 osteosarcoma cell lines via the caspase-3- and caspase-8-dependent apoptotic pathway.

In the present study, a potential therapeutic pathway was identified, targeted by SK and ADM to induce apoptosis in osteosarcoma cells. The cooperation of SK with ADM resulted in enhanced apoptosis in osteosarcoma cells via the induction of apoptotic cell death, accompanied by upregulation in the expression levels of caspase-3, caspase-8, Bax and PARP. SK, as a sensitization agent and chemotherapeutic drug, is of clinical value and may serve as a standard for the development of other Chinese herbal medicines. Limitations of the present study include the lack of in vivo experiments; therefore, additional investigations using animal models are required in the future.

In conclusion, data obtained in the present study showed that the suppression of growth in osteosarcoma by SK in combination with ADM resulted from the induction of apoptosis in vitro. These findings may lead to further investigations on Chinese herbal medicines with unexpected antitumor effects.

\section{References}

1. Cormier JN and Pollock RE: Soft tissue sarcomas. CA Cancer J Clin 54: 94-109, 2004

2. Liao YX, Zhou CH, Zeng H, Zuo DQ, Wang ZY, Yin F, Hua YQ and Cai ZD: The role of the CXCL12-CXCR4/CXCR7 axis in the progression and metastasis of bone sarcomas (Review). Int J Mol Med 32: 1239-1246, 2013

3. Isakoff MS, Bielack SS, Meltzer P and Gorlick R: Osteosarcoma: Current treatment and a collaborative pathway to success. J Clin Oncol 33: 3029-3035, 2015.

4. Jiang Y, Ludwig J and Janku F: Targeted therapies for advanced Ewing sarcoma family of tumors. Cancer Treat Rev 41: 391-400, 2015.

5. McTiernan A, Jinks RC, Sydes MR, Uscinska B, Hook JM, van Glabbeke M, Bramwell V, Lewis IJ, Taminiau AH, Nooij MA, et al: Presence of chemotherapy-induced toxicity predicts improved survival in patients with localised extremity osteosarcoma treated with doxorubicin and cisplatin: A report from the European Osteosarcoma Intergroup. Eur J Cancer 48: 703-712, 2012.

6. Ferrari S, Ruggieri P, Cefalo G, Tamburini A, Capanna R, Fagioli F, Comandone A, Bertulli R, Bisogno G, Palmerini E, et al: Neoadjuvant chemotherapy with methotrexate, cisplatin, and doxorubicin with or without ifosfamide in nonmetastatic osteosarcoma of the extremity: An Italian sarcoma group trial ISG/OS-1. J Clin Oncol 30: 2112-2118, 2012.

7. Khaw AK, Hande MP, Kalthur G and Hande MP: Curcumin inhibits telomerase and induces telomere shortening and apoptosis in brain tumour cells. J Cell Biochem 114: 1257-1270, 2013.

8. James MI, Iwuji C, Irving G, Karmokar A, Higgins JA, Griffin-Teal N, Thomas A, Greaves P, Cai H, Patel SR, et al: Curcumin inhibits cancer stem cell phenotypes in ex vivo models of colorectal liver metastases, and is clinically safe and tolerable in combination with FOLFOX chemotherapy. Cancer Lett 364: 135-141, 2015.

9. Blakemore LM, Boes C, Cordell R and Manson MM: Curcumin-induced mitotic arrest is characterized by spindle abnormalities, defects in chromosomal congression and DNA damage. Carcinogenesis 34: 351-360, 2013.

10. Patil S, Lis LG, Schumacher RJ, Norris BJ, Morgan ML, Cuellar RA, Blazar BR, Suryanarayanan R, Gurvich VJ and Georg GI: Phosphonooxymethyl prodrug of triptolide: Synthesis, physicochemical characterization, and efficacy in human colon adenocarcinoma and ovarian cancer xenografts. J Med Chem 58: 9334-9344, 2015

11. Chen X, Guo J, Bao J, Lu J and Wang Y: The anticancer properties of Salvia miltiorrhiza Bunge (Danshen): A systematic review. Med Res Rev 34: 768-794, 2014. 
12. Zhuang SR, Chiu HF, Chen SL, Tsai JH, Lee MY, Lee HS, Shen YC, Yan YY, Shane GT and Wang CK: Effects of a Chinese medical herbs complex on cellular immunity and toxicity-related conditions of breast cancer patients. Br J Nutr 107: 712-718, 2012.

13. Chen J, Xie J, Jiang Z, Wang B, Wang Y and Hu X: Shikonin and its analogs inhibit cancer cell glycolysis by targeting tumor pyruvate kinase-M2. Oncogene 30: 4297-4306, 2011.

14. Andújar I, Recio MC, Giner RM and Ríos JL: Traditional Chinese medicine remedy to jury: The pharmacological basis for the use of shikonin as an anticancer therapy. Curr Med Chem 20: 2892-2898, 2013.

15. Andújar I, Ríos JL, Giner RM and Recio MC: Pharmacological properties of shikonin-a review of literature since 2002. Planta Med 79: 1685-1697, 2013

16. Anninga JK, Gelderblom H, Fiocco M, Kroep JR, Taminiau AH, Hogendoorn PC and Egeler RM: Chemotherapeutic adjuvant treatment for osteosarcoma: Where do we stand? Eur J Cancer 47: $2431-2445,2011$

17. Li S, Sun W, Wang H, Zuo D, Hua Y and Cai Z: Research progress on the multidrug resistance mechanisms of osteosarcoma chemotherapy and reversal. Tumour Biol 36: 1329-1338, 2015.

18. de Carné Trécesson S, Guillemin Y, Bélanger A, Bernard AC, Preisser L, Ravon E, Gamelin E, Juin P, Barré B and Coqueret O: Escape from p21-mediated oncogene-induced senescence leads to cell dedifferentiation and dependence on anti-apoptotic Bcl-xl and MCL1 proteins. J Biol Chem 286: 12825-12838, 2011.

19. PosthumaDeBoer J, Witlox MA, Kaspers GJ and van Royen BJ: Molecular alterations as target for therapy in metastatic osteosarcoma: A review of literature. Clin Exp Metastasis 28: 493-503, 2011.
20. Momparler RL, Karon M, Siegel SE and Avila F: Effect of adriamycin on DNA, RNA, and protein synthesis in cell-free systems and intact cells. Cancer Res 36: 2891-2895, 1976.

21. Tewey KM, Rowe TC, Yang L, Halligan BD and Liu LF: Adriamycin-induced DNA damage mediated by mammalian DNA topoisomerase II. Science 226: 466-468, 1984.

22. Bilim VN, Tomita Y, Kawasaki T, Takeda M and Takahashi K: Adriamycin (ADM) induced apoptosis in transitional cell cancer (TCC) cell lines accompanied by p21 WAF1/CIP1 induction. Apoptosis 2: 207-213, 1997.

23. Bilim V, Kawasaki T, Takahashi K and Tomita Y: Adriamycin induced $\mathrm{G} 2 / \mathrm{M}$ cell cycle arrest in transitional cell cancer cells with wt p53 and p21(WAF1/CIP1) genes. J Exp Clin Cancer Res 19: 483-488, 2000.

24. Voorhees PM, Orlowski RZ, Mulkey F, Watson P, Geyer S, Sanford BL, Bennett E, Chanan-Khan AA, Bloomfield CD and Larson RA: Long-term outcomes for newly-diagnosed multiple myeloma patients treated with pegylated liposomal doxorubicin and bortezomib: Final results of CALGB (Alliance) 10301, a multicentre phase II study. Br J Haematol 171: 373-377, 2015.

25. Taylor RC, Cullen SP and Martin SJ: Apoptosis: Controlled demolition at the cellular level. Nat Rev Mol Cell Biol 9: 231-241, 2008.

26. Oliver FJ, de la Rubia G, Rolli V, Ruiz-Ruiz MC, de Murcia G and Murcia JM: Importance of poly (ADP-ribose) polymerase and its cleavage in apoptosis. Lesson from an uncleavable mutant. J Biol Chem 273: 33533-33539, 1998. 